\title{
Investigation of wetting and hydrophobic properties of bitumen modified with different vegetable oils
}

\author{
Sercan Serin $^{\mathrm{a}}{ }^{*}$ (iD), Sümeyye Elif Demirezer ${ }^{\mathrm{b}}$ (D) \\ aDepartment of Civil Engineering, Faculty of Engineering, Osmaniye Korkut Ata University, Osmaniye, Turkey $\longrightarrow$ \\ ${ }^{b}$ Department of Civil Engineering, Institute of Natural Sciences, Düzce University, Düzce, Turkey
}
Highlights
- Bitumen modified with different vegetable oils.
- Physical, mechanical and hydrophobic properties of bitumen were determined.

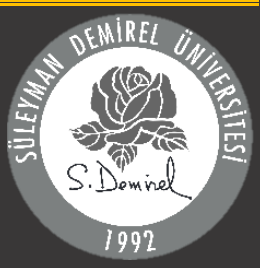

- Hydrophobic properties of bitumen can be improved with vegetable oils.

- Vegetable oils cause serious changes in the physical and mechanical properties of bitumen.

\begin{abstract}
In this study, the effects of oils obtained from vegetable products on the physical, mechanical and hydrophobic properties of bitumen were investigated. Within the scope of the study, six different vegetable oils were used for bitumen modification: hemp oil, flax seed oil, laurel ghee, centaury oil, castor oil, pine turpentine oil. These are $100 \%$ pure vegetable oils, obtained by using cold press method. The bitumen was modified by adding vegetable oils to bitumen with the proportions of $3 \%, 5 \%$ and $7 \%$. Including the reference group, 19 sample groups were formed with six different vegetable oils by using three different mixing ratios. The physical and mechanical properties of the prepared bitumen samples were determined, according to their contact angles their sensitivity to water, surface wetting and hydrophobic properties were determined by using the IMAGEJ program. As a conclusion of the results of the studies, it has been introduced that different vegetable oils cause serious changes in the physical and mechanical properties of bitumen, and in addition, bitumen modified with vegetable oils can make a significant contribution to removal of water from the road surface which is a major problem for traffic safety.
\end{abstract}

Information
24.09.2021
Received:

22.12.2021

Accepted:

24.12.2021

Keywords: Bitumen, modification, hydrophobic, water sensitivity, vegetable oils, hemp oil, flax seed oil,

laurel ghee, centaury oil, castor oil, pine turpentine oil.

\section{Introduction}

In this study, in order to eliminate the damage caused by water and moisture on bitumen, the change in the hydrophobic property of bitumen as a result of modification with different vegetable oils has been investigated.

Bitumen is a chemical having a high boiling point that contains hydrocarbons in its structure. Bitumen is used as a binder for the aggregates in asphalt mixture to hold together. Its road surface properties are known to play an important role in traffic safety. As a result of the technology supply and greater demand from road users, surface properties of roads are becoming increasingly significant in the construction and maintenance of roads for comfort and safety [1].
Bituminous coatings provide good driving comfort to drivers by means of their smooth surface feature. Roads with smooth surfaces would also reduce the risk of accidents in rainy weather. Because the water film thickness is related to mean texture depth of pavement surface. There is consensus among many researchers about the effect of the surface properties of the coating on accident risks [2-4].

Moisture damage at the interfaces of bitumen-aggregate in the binder has been studied by various researchers [5, 6]. In these studies, moisture damage behavior in asphalt pavement was investigated to measure the adhesion strength of the asphalt binder. Lately, the surface energy of bitumen and aggregate has been empirically associated with moisture-related damage of asphalt concrete [6]. 
Moisture damage can be defined as loss of strength and durability in asphalt mixes due to moisture. Moisture damage occurs due to loss of bonding between asphalt cement and fine and coarse aggregate. On the other hand, the effect of repetitive loads causes the pavement to become more sensitive to moisture [5].

For reasons such as eliminating the negative effects mentioned above, and on the other hand, to develop sufficient elastic properties with improved resistance to permanent deformation, to prevent cracks, to provide bitumen the necessary rigidity at high temperatures, to provide flexibility at low temperatures, to provide bitumen a high storage stability and resistance to thermal deformations, it is seen that bitumen has been modified using various additives [7].

In this study, in order to eliminate the damage caused by water and moisture on bitumen, the change in the hydrophobic property of bitumen as a result of modification with different vegetable oils has been investigated.

\section{Hydrophobic and Hydrophilic Property}

As a result of the effect of the potential energies of liquids, the molecules remaining in the interior are less dense than the molecules on the surface of the liquid, so that surface tension occurs on the surfaces of liquids. Thus, liquid substances form different contact angles with solid surfaces. If contact angles are greater than $90^{\circ} \mathrm{C}$, it is hydrophobic, if less than $90^{\circ} \mathrm{C}$ it is hydrophilic (Figure 1). It is defined as superhydrophobic if greater than $140^{\circ}$ $\mathrm{C}$, and superhydrophilic if closer to $0^{\circ} \mathrm{C}$ [8].

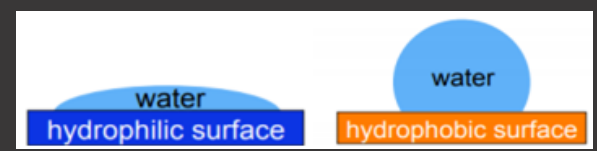

Figure 1. Hydrophilic and hydrophobic surface, respectively [9].

The term surface contact angle, first discovered by Thomas Young in 1805, is one of the methods used in determining the non-wetting state of solids, their surface energy properties, liquid-solid interface and solid surface energy at minimum equilibrium distance [10].

The expression of contact angle $(\theta)$ depending on surface and interface energies, also known as Young's Equation, is shown below [11].

YsgCos $\alpha=Y k g-Y k s$

In this equilibrium;

Ysg: Surface tension (energy) of the liquid $\left(\mathrm{mJ} / \mathrm{m}^{2}\right.$ )

Yks: Energy of the solid - liquid interface $\left(\mathrm{mJ} / \mathrm{m}^{2}\right)$,
A modal representation of the parameters used in the equation is presented in Figure 2 below.

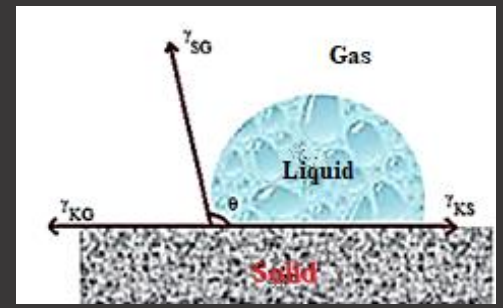

Figure 2. Representation of contact angle of a water drop with solid surface [12].

Materials with altered hydrophobic or hydrophilic properties by improving their performance with various additives are found in many sectors on production of products [10-22]. In addition, this issue has been widely discussed in scientific studies in different areas such as soil improvement, coating of materials, enhancing hydrophobic properties to concrete and cement-based materials, and reducing the effect of corrosion in reinforcement steel $[8,11,23-28]$.

In the study conducted by Lal et al. [29], wetting and drying of a hydrophobic macroporous setting such as porous asphalt (PA) was investigated under different environmental loads. Three different types of porous asphalt with different pore sizes were sealed on all surfaces except the upper one, and they were tested by pouring water droplets on them.

In 2018, Zakerzadeh et al. aimed to measure the contact angle of the material sprayed to the surface, in the presence of various hydrophobic coatings with a certain weight percentage. In asphalt samples, the contact angle measured with 8 different hydrophobic materials was investigated. On average, they increased the contact angle of the asphalt surfaces from 75 to 156, making the surface of the asphalt pavement superhydrophobic [30].

Gao et al. [31] prepared samples of super hydrophobic asphalt concrete by using modified hydrophobic materials and nanomaterials in their study. Anti-icing and de-icing performance of superhydrophobic asphalt concrete has been investigated on different designs. Simulation test and theoretical analysis were used together in the study, and it was compared with conventional asphalt concrete. The researchers examined the anti-ice properties of the samples prepared by using contact angle and surface energy.

Nahvi et al. [32], in their study, optimized the superhydrophobicity and slip resistance of hydrophobic coatings on asphalt concrete surfaces. It has been tried to make asphalt concrete superhydrophobic by using different spraying times and various dosages of chemicals. In order to determine the superhydrophobicity and shear resistance of coated asphalt concrete, water

Ykg: Energy of the solid surface $\left(\mathrm{mJ} / \mathrm{m}^{2}\right)$ 
contact angle and friction coefficient were measured at the micro-tissue.

Han et al. [33] aimed to obtain a hydrophobic emulsified asphalt coating on asphalt pavement by adding a hydrophobic agent to the emulsified asphalt in their research. Factors affecting the hydrophobic property, such as the roughness of the hydrophobic material, the dosage and the joining method were taken into account. Anti-ice property (ice-repellency) of the prepared samples was characterized by the contact angle.

Han et al. [34] have made a research to overcome the shortcomings in durability of hydrophobic emulsified asphalt pavement caused by poor slip resistance performance and poor wear resistance. In the study, hydrophobic emulsified asphalt modified with waterborne epoxy resin was used. The wet track abrasion test and load wheel test were performed to evaluate the optimal asphalt content of the micro surfacing mixture.

Dalhat et al. [35] used recycled low and high density PolyEthylene (rLDPE and rHDPE) to transform the asphalt surface from hydrophobic to Super Hydrophobic. Asphalt surfaces have been modified using different curing times. Then, the roughness and water contact angle of the prepared samples were analyzed.

In this study, it was aimed to modify the pure bitumen used on asphalt roads with different vegetable oils. Thus, the change in wetting and hydrophobic properties of bitumen was investigated. In the literature search, there is no study found where vegetable oils are used to improve the hydrophobic properties of bituminous materials. In this context, six different vegetable oils obtained by cold press were used for bitumen modification, and the change in surface contact angle was compared with the reference sample. On the other hand, the changes in the physical and mechanical properties of the modified bitumen were also comparatively studied.

\section{Material}

\subsection{Bitumen}

The bitumen B 50/70 used in the study was obtained from the asphalt production facility used in urban road construction. Basic physical experiments were carried out on bitumen before it was modified. The results of the experimental studies are presented in a table below (Table 1).

\subsection{Bitumen modification with vegetable oils}

Six different vegetable oils were used in the study to modify bitumen. These are $100 \%$ pure vegetable oils, obtained by using cold press method. Six different oil types were chosen for the study: Flax seed oil, laurel seed oil, hemp seed oil, centaury oil, castor oil, pine turpentine oil. Especially cold pressed vegetable oils were preferred in the study, since they were obtained only by mechanical method without heat treatment. On the other hand, while the vegetable oils used in the study were preferred, the plants that are widely produced in our country or that are aimed to be expanded were taken into consideration.

Table 1. Basic physical properties of bitumen.

\begin{tabular}{lcc}
\hline \hline Tests & $\begin{array}{c}\text { Specification } \\
\text { Limits }\end{array}$ & Test Results \\
\hline Ductility $(\mathrm{cm})$ & $>100$ & $>100$ \\
Nicholson test $(\%)$ & $>50$ & $>50$ \\
Softing Point $\left({ }^{\circ} \mathrm{C}\right)$ & - & 47.70 \\
Penetration $(1 / 10 \mathrm{~mm})$ & - & 62.80 \\
Bitumen Class & - & $B 50 / 70$ \\
Specific Gravity $\left(\mathrm{gr} / \mathrm{cm}^{3}\right)$ & - & 0.99 \\
\hline \hline
\end{tabular}

Within the scope of the study, different ratios were used to determine to what extent the vegetable oils changed the water and moisture sensitivity of bitumen. In this process, bitumen was modified by adding each vegetable oil in three different proportions (3\%, 5\%, 7\%). Thus, modified bitumen with six different oils having three different contents has been developed. In addition, after the reference bitumen sample is included, a total of 19 different groups were formed in the study. The abbreviations for the formed groups are presented in Table 2. Abbreviations of the modified bitumen by adding vegetable oils to pure bitumen in different proportions are shown in Figure 3.

Table 2. Coding the mixing ratios.

\begin{tabular}{lll}
\hline \hline & $\%$ Content & Coding \\
\hline Reference Bitumen Sample (RBS) & - & RBS \\
Hemp Seed Oil (HSO) & 3 & HSO3 \\
& 5 & HSO5 \\
Flax Seed Oil (FSO) & 7 & HSO7 \\
& 3 & FSO3 \\
Laurel Seed Oil (LSO) & 5 & FSO5 \\
& 7 & FSO7 \\
Centaury Oil (CEO) & 3 & LSO3 \\
& 5 & LSO5 \\
Castor Oil (CAO) & 7 & LSO7 \\
& 3 & CEO3 \\
Pine Turpentine Oil & 5 & CEO5 \\
(PTO) & 7 & CEO7 \\
& 3 & CAO3 \\
\hline \hline
\end{tabular}

\section{Method}

In this study, an image analysis program called IMAGEJ was used to determine the sensitivity of modified bitumen to water and to reveal their hydrophobic properties. This program is very practical, and it gives fast results. The photos of the drop were taken to measure the contact angle of the water drop on the bituminous 
mixture with the solid surface, so that the drop was fixed and perpendicular to the surface. These photos transferred to the IMAGEJ program. The contact angle for 19 samples was analyzed one by one under the Contact Angle tab. Thus, it was revealed how differently the prepared mixtures react to water. In Figure 4, the picture of the contact angle determination of the samples is presented.

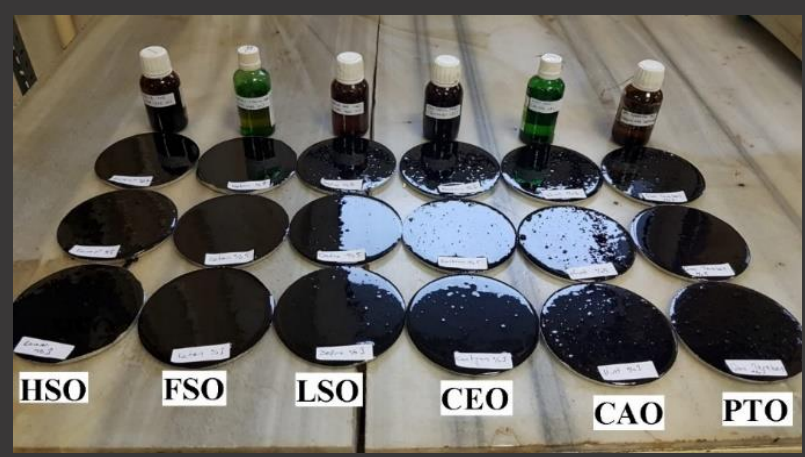

Figure 3. Samples prepared by adding different proportions of vegetable oil.

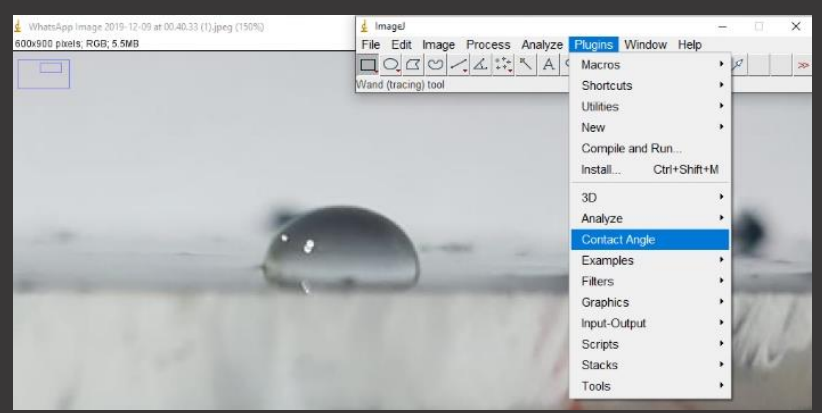

Figure 4. Contact angle analysis done by IMAGEJ program interface.

\section{Research Findings}

\subsection{Physical tests on modified bitumen}

Some experiments have been carried out to determine the changes in the physical and mechanical properties of bitumen after vegetable oils added in different proportions to bitumen. The results were examined in detail (Table 3).

According to the results of softening point test, the softening value of our reference samples was determined as $47.70^{\circ} \mathrm{C}$. In the mixture with FSO, CAO and LSO additives, when the effects were examined according to the varying ratio of the vegetable oils in the mixture, it was observed that the softening point increases along with the increase in the ratio of vegetable oil. On the contrary, in other groups (HSO, CEO, PTO), it was observed that the softening points of the bitumen decreased with the increase in the oil content.

When the effects were examined according to the varying ratio of the vegetable oils in the mixture, in all groups, it was determined that as the rate of vegetable oil in the bitumen is increased, the penetration value increases. This shows that the oils in the mixture increase the processability of the mixture.

The specific gravity values of all groups except FSO and LSO increased along with the increase in the oil content. This result is thought to be directly related to the specific weight of the oils added in the mixture.

Also the ductility and Nicholson stripping test results were examined for all groups, it is determined that all groups meet the specification limits.

Table 3. The physical test results of modified bitumen.

\begin{tabular}{|c|c|c|c|c|c|c|}
\hline Vegetable Oil & $\begin{array}{l}\text { V. Oil Content } \\
\text { (\%) }\end{array}$ & $\begin{array}{l}\text { Softening Point } \\
\left({ }^{\circ} \mathrm{C}\right)\end{array}$ & $\begin{array}{c}\text { Penetration } \\
(1 / 10 \mathrm{~mm})\end{array}$ & $\begin{array}{l}\text { Specific Gravity } \\
\left(\mathrm{gr} / \mathrm{cm}^{3}\right)\end{array}$ & $\begin{array}{l}\text { Ductility } \\
(\mathrm{cm})\end{array}$ & $\begin{array}{c}\text { Nicholson test } \\
(\%)\end{array}$ \\
\hline \multirow[t]{2}{*}{ RBS } & 0 & 47.70 & 62.80 & 0.99 & & \\
\hline & 3 & 51.10 & 63.70 & 1.21 & & \\
\hline \multirow[t]{3}{*}{ HSO } & 5 & 50.50 & 76.60 & 1.23 & & \\
\hline & 7 & 48.75 & 107.00 & 1.25 & & \\
\hline & 3 & 45.60 & 82.00 & 1.35 & & \\
\hline \multirow[t]{3}{*}{ FSO } & 5 & 47.75 & 91.30 & 1.27 & & \\
\hline & 7 & 53.00 & 100.00 & 1.19 & & \\
\hline & 3 & 48.75 & 67.60 & 1.27 & & \\
\hline \multirow[t]{3}{*}{ LSO } & 5 & 55.00 & 85.70 & 1.22 & & \\
\hline & 7 & 55.50 & 93.30 & 1.18 & $>100$ & $>50$ \\
\hline & 3 & 53.15 & 63.30 & 1.12 & & \\
\hline \multirow[t]{3}{*}{ CEO } & 5 & 51.25 & 72.00 & 1.21 & & \\
\hline & 7 & 48.05 & 84.30 & 1.25 & & \\
\hline & 3 & 50.25 & 61.00 & 1.22 & & \\
\hline \multirow[t]{3}{*}{ CAO } & 5 & 50.30 & 66.60 & 1.41 & & \\
\hline & 7 & 53.50 & 93.30 & 1.5 & & \\
\hline & 3 & 56.50 & 72.70 & 1.21 & & \\
\hline \multirow[t]{2}{*}{ PTO } & 5 & 53.25 & 123.30 & 1.32 & & \\
\hline & 7 & 49.00 & 144.60 & 1.35 & & \\
\hline
\end{tabular}




\subsection{EDX analysis of modified bitumen}

EDX point or area analysis; It gives the element distribution of selected area on the sample surface in percentage. By applying high voltage and high $\mathrm{pA}$, the concentration of $X$-rays is increased, by absorbing from the $200 \mathrm{~nm}$ surface of the sample, it gives results.

The results of electron-dispersed X-ray spectrometer analysis of 19 samples are given in Table 4. The information about the chemical composition of the mixtures was obtained by EDX analysis. In Figure 5, the change of EDX analysis values within the same group is presented. The change that occurred with the increase in the amount of oil in the FSO group was compared with the reference sample. As a result of EDX analysis, it is observed that the structures peaking at carbon (C), oxygen (O) and sulfur (S) elements. In the reference sample, it was observed that the majority of the composition (86.8\%) was carbon, which is followed by $10.55 \%$ oxygen and $2.64 \%$ sulfur. When the FSO groups are examined, it was observed that the $3 \%$ of flax seed oil added to the mixture reduces the amount of carbon and sulfur and increases the amount of oxygen in the modified bitumen. With the increase of flaxseed oil content, it was observed that there was an increase in the amount of carbon and sulfur in both solution groups with $5 \%$ and $7 \%$ of oil content in modified bitumen, whereas the amount of oxygen decreased.

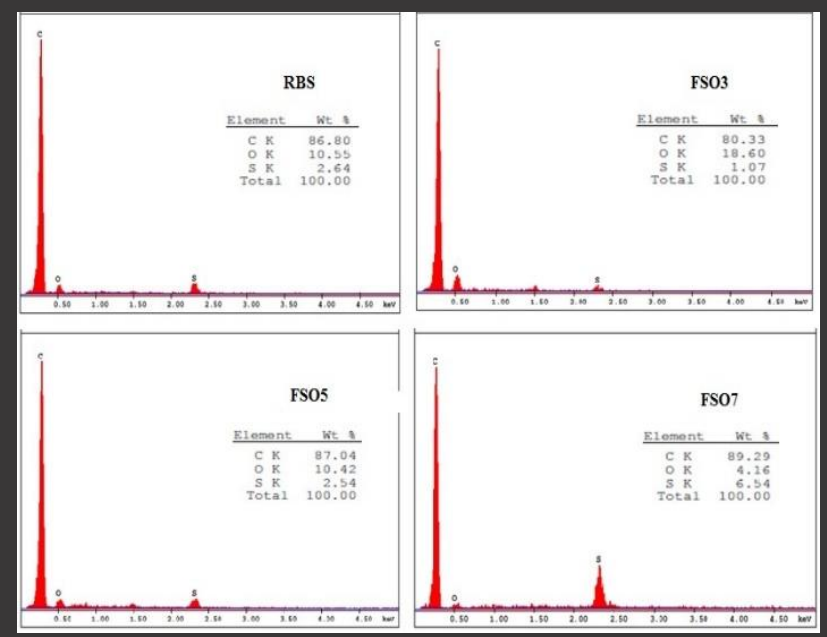

Figure 5. The change of the values of EDX analysis within the same group.
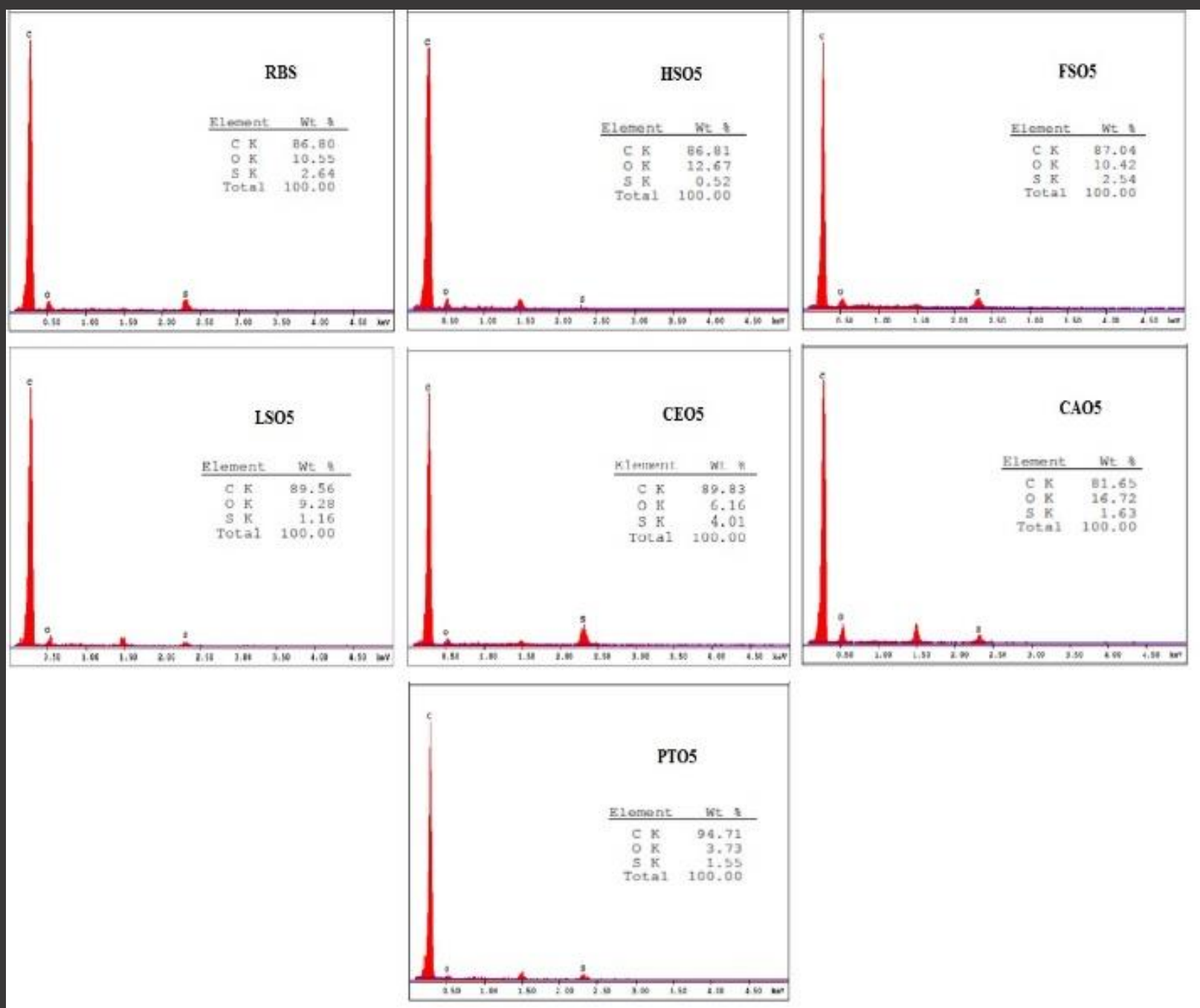

Figure 6. Change of the values of EDX analysis within different groups. 
In Figure 6, the changes that occur when different vegetable oils are added to bitumen at the same ratio have been examined. It has been determined that the carbon content of the HSO group was close to the reference sample, while its sulfur value decreased, and oxygen value increased. It has been determined that compared to the reference sample, carbon values increase, and oxygen values decrease in groups having $5 \%$ of oil FSO, LSO, CEO and PTO groups. In the CAO group having $5 \%$ of oil on the other hand, it has been determined that the carbon content is lower than the reference and the oxygen content increased. Except in CEO group in all groups, compared to the reference, a decrease in sulfur content was determined. The Aluminum peaks (Al) found in the analyzes were not included in the evaluation, since it is believed that the mixture samples were caused from the containers where they were stored.

The EDX results of the sample groups given above and of all other groups are presented in Table 4.

\subsection{Hydrophobic properties of modified bitumen}

19 different prepared samples were transferred to flat plates with a manner to have a flat surface. In order to determine the hydrophobicity and water sensitivity of the modified bitumen mixtures, a drop of water was dropped on the bitumen mixtures, which were poured into the container and completely hardened, and images were taken and analyzed (Figure 7).

The photographs were taken in a way that the drop was seen fixed and vertical on the surface to measure the contact angle between water drop on the bituminous mixture with the solid surface. They were transferred to the IMAGEJ program. The contact angle is analyzed one by one under Contact Angle tab for the 19 samples. Figure 8 shows the determination of the values of angles after the analysis made with IMAGEJ for the reference sample and different samples.

Table 4. The results of EDX analysis.

\begin{tabular}{lccc}
\hline & \multicolumn{3}{c}{ Elements $\%$} \\
\hline Coding & $\mathrm{C}$ & $\mathrm{O}$ & $\mathrm{S}$ \\
RBS & 86.80 & 10.55 & 2.64 \\
HSO3 & 89.00 & 7.30 & 3.70 \\
HSO5 & 86.81 & 12.67 & 0.52 \\
HSO7 & 89.29 & 9.60 & 1.11 \\
FSO3 & 80.33 & 18.6 & 1.07 \\
FSO5 & 87.04 & 10.42 & 2.54 \\
FSO7 & 89.29 & 4.16 & 6.54 \\
LSO3 & 93.13 & 2.84 & 4.03 \\
LSO5 & 89.56 & 9.28 & 1.16 \\
LSO7 & 87.76 & 11.39 & 0.86 \\
CEO3 & 91.74 & 7.23 & 1.02 \\
CEO5 & 89.83 & 6.16 & 4.01 \\
CEO7 & 92.66 & 2.42 & 4.93 \\
CAO3 & 91.09 & 5.86 & 3.05 \\
CAO5 & 81.65 & 16.72 & 1.63 \\
CAO7 & 86.43 & 9.57 & 4.00 \\
PTO3 & 91.82 & 6.88 & 1.30 \\
PTO5 & 94.71 & 3.73 & 1.55 \\
PTO7 & 91.63 & 2.52 & 5.85 \\
\hline \hline
\end{tabular}

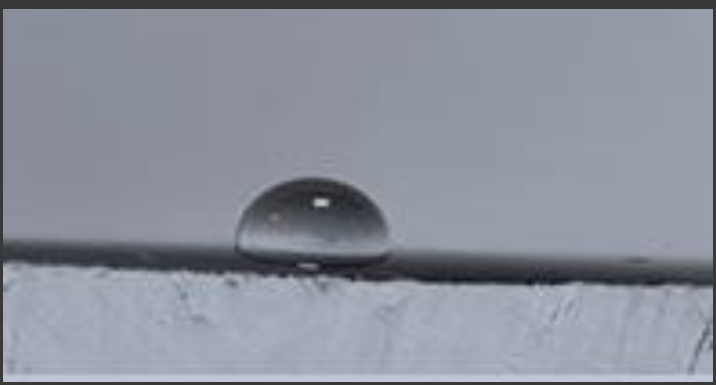

Figure 7. Position of the water drop on the bituminous mixture.

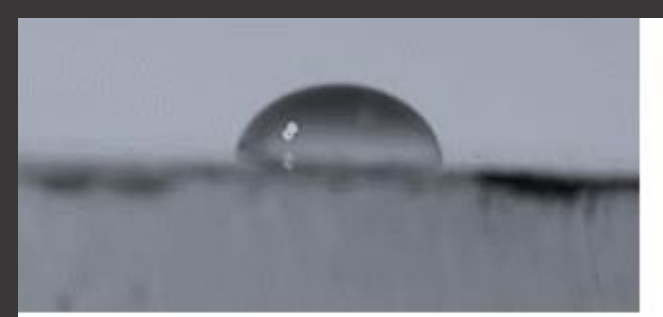

(a)

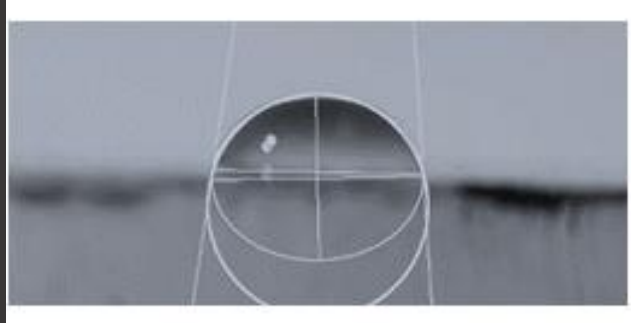

(b)
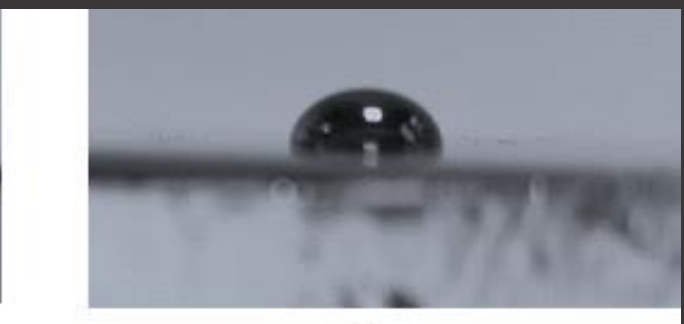

(c)

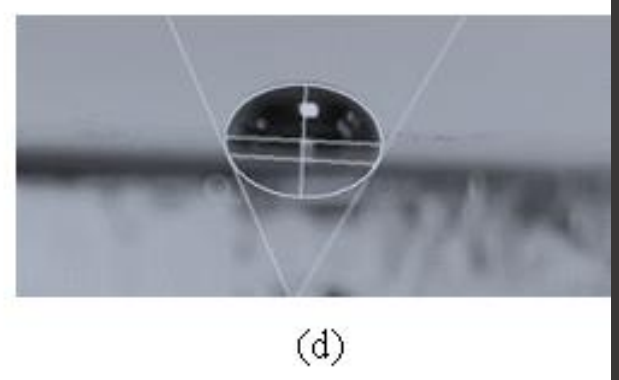

Figure 8. Image of water drop on bitumen surface before and after the analysis (a) Reference sample, (b) Reference sample after the analysis, (c) CEO3 sample, (d) CEO3 sample after the analysis. 
Table 5. The results of contact angle analysis of all samples.

\begin{tabular}{lccccccccc}
\hline \hline & Angle & Length & Theta C & Uncertainty & Theta Left & Theta Right & Theta E & Radius & Contact Angle \\
\hline RBS & 178.91 & 264.05 & 107.80 & 0.50 & 97.60 & 94.70 & 96.20 & 138.70 & 72.20 \\
HSO3 & 177.43 & 89.09 & 98.90 & 0.30 & 97.00 & 97.30 & 97.20 & 45.10 & 81.10 \\
HSO5 & -178.41 & 108.04 & 94.80 & 0.50 & 80.60 & 92.50 & 86.60 & 54.22 & 85.20 \\
HSO7 & 178.94 & 108.02 & 107.50 & 0.80 & 101.80 & 101.40 & 101.60 & 56.61 & 72.50 \\
FSO3 & -179.54 & 124.00 & 96.90 & 0.40 & 83.60 & 87.20 & 85.40 & 62.45 & 83.10 \\
FSO5 & -179.56 & 130.00 & 94.00 & 0.70 & 77.70 & 79.10 & 78.40 & 65.17 & 86.00 \\
FSO7 & -178.99 & 113.02 & 90.00 & 1.10 & 74.40 & 75.40 & 74.90 & 56.56 & 90.00 \\
LSO3 & -179.53 & 123.00 & 93.30 & 0.70 & 86.00 & 84.90 & 85.40 & 61.63 & 86.70 \\
LSO5 & 180.00 & 111.00 & 94.10 & 0.80 & 85.70 & 85.00 & 85.40 & 55.67 & 85.90 \\
LO7 & 180.00 & 129.00 & 99.70 & 0.60 & 88.40 & 90.40 & 89.40 & 65.42 & 80.30 \\
CEO3 & 174.38 & 281.26 & 63.50 & 4.90 & 62.60 & 61.90 & 62.20 & 165.13 & 116.50 \\
CEO5 & 177.84 & 106.08 & 94.30 & 0.50 & 85.50 & 86.00 & 85.80 & 53.20 & 85.70 \\
CEO7 & 179.10 & 128.02 & 95.40 & 0.50 & 85.40 & 79.50 & 82.40 & 64.29 & 84.60 \\
CAO3 & 179.54 & 125.00 & 91.40 & 1.00 & 80.10 & 76.90 & 78.50 & 62.59 & 88.60 \\
CAO5 & 178.97 & 111.02 & 97.20 & 0.70 & 85.00 & 84.30 & 84.60 & 55.98 & 82.80 \\
CAO7 & 180.00 & 103.00 & 94.40 & 0.50 & 86.80 & 84.30 & 85.60 & 52.14 & 85.60 \\
PTO3 & 177.86 & 107.07 & 94.20 & 1.10 & 88.60 & 81.70 & 85.20 & 53.70 & 85.80 \\
PTO5 & 179.55 & 126.00 & 98.60 & 0.40 & 89.10 & 89.70 & 89.40 & 63.76 & 81.40 \\
PTO7 & 177.96 & 281.18 & 102.40 & 0.50 & 95.00 & 91.10 & 93.00 & 144.00 & 77.60 \\
\hline \hline
\end{tabular}

After modification of bitumen with all vegetable oils used in the study and the use of them in different proportions, the obtained values from contact angle analysis study are presented in Table 5.

When Figure 9 is examined, it has been observed that the approximate contact angle value of the reference sample, which is pure bitumen, is $72.2^{\circ}$. When the samples modified by adding vegetable oil in different proportions are examined, it is observed that the contact angle value exceeds that of the reference sample in all mixtures. When the groups were examined, it was found that the highest change in contact angle were found in CEA groups. The highest contact angle was formed as $116.5^{\circ}$ in the CEO3 group. The lowest contact angle value was formed as $72.50^{\circ}$ in the sample groups modified with adding $7 \%$ hemp seed oil (HSO7). When each group was examined separately, it was observed that with the modification of bitumen with hemp seed oil, the highest contact angle value was found in the HSO5 group. After reaching ratio of $5 \%$ of additive, the contact angle also started to decrease gradually; however, in all three groups, the contact angle value didn't drop below that of reference sample. When the bitumen samples modified with flaxseed oil (FSO) were examined, it was observed that the contact angle value increased with the increase in the additive ratio. In FSO groups, the lowest contact angle value was reached in FSO3 samples with $83.10^{\circ}$, and the highest contact angle value was obtained in FSO7 samples with $90^{\circ}$. When the groups with laurel seed oil (LSO) were examined, it was observed that the contact angle value tended to decrease with the increase of the oil content ratio. The contact angle was $86.7^{\circ}$ in the LSO3 group, whereas it was calculated as $80.30^{\circ}$ in the LSO7 groups. When the bitumen groups (CEO) modified with centaury oil were examined, it was observed that the contact angle value decreased with the increase in the additive ratio. In this group, with $84.60^{\circ}$, the lowest contact angle value was reached in the CEO7 group. The lowest contact angle was $88.60^{\circ}$ in bitumen groups, in which castor oil added (CAO), the lowest contact angle value was observed in the CAO5 group with $82.80^{\circ}$. In pine turpentine oil added groups (PTO), the contact angle values of modified bitumen tended to decrease with the increase the in additive ratio. While the average contact angle was $85.80^{\circ}$ in the PTO3 group and $81.40^{\circ}$ in the PTO5 group, it was $77.60^{\circ}$ in the PTO7 group which is also the lowest contact value within the group. It is seen in Figure 9 that the $\mathrm{CEO} 3$ and FSO3 groups are above the hydrophobic minimum limit value of $90^{\circ}$.

\section{Conclusions}

Studies, besides determining the surface wetting, water sensitivity and hydrophobic properties of bitumen, the main binder material used in bituminous road construction, has showed what kind of differences will occur in physical and mechanical properties with the change of these features of bitumen. Considering the removal of water from the surface, which is an important traffic problem for highways, and the damage of water to the road, it offers very important results. Although it is known that the basic physical properties of the bituminous binders can be changed with different modified additives, together with the change in its sensitivity to water and its hydrophobic properties, this detailed information could not be found in the literature. In this context, this study provides the reader with an original information.

Bituminous binder was modified by using six different vegetable oils and the contact angle value expressing the sensitivity to water were found. In all studies, the water sensitivity of the bituminous binder, modified with vegetable oils, can be further reduced and thus hydrophobic properties can be achieved. 


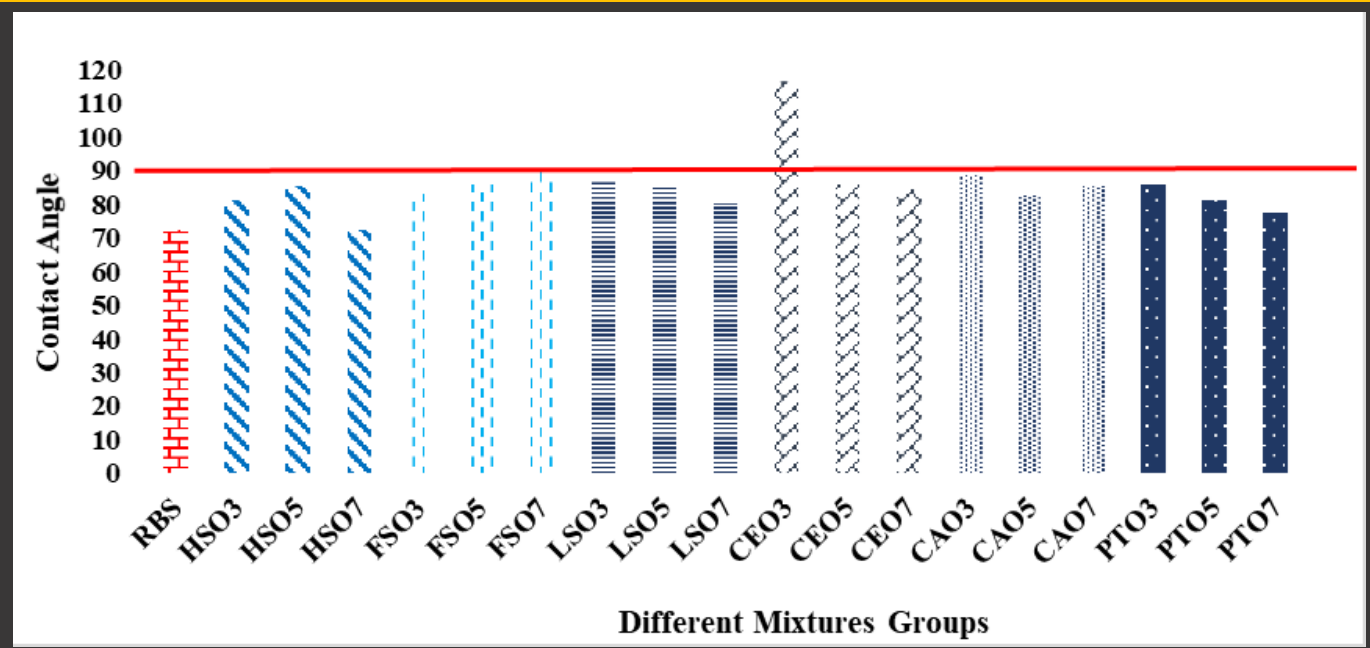

Figure 9. Contact angle changes of different groups.

When bitumen is evaluated considering basic physical properties, the softening point value of our reference sample was determined as $47.70^{\circ} \mathrm{C}$ according to the results of the softening point test. If the change that occurs with the increase in the ratio of vegetable oil content added to bitumen during modification considered, it is observed that the softening point increases along with the increase in the ratio of vegetable oil content in the mixtures having FSO, CAO and LSO additives. In HSO, CEO and PTO groups on the other hand, it was determined that the softening points of the bituminous binders decreased with the increase in the vegetable oil content. This shows that some vegetable oils increase the sensitivity of bitumen to heat, whereas others decrease it.

When penetration values, which is another basic physical property, are examined; it was determined that the average penetration value of the reference samples was $62.8 \mathrm{~mm}$, whereas there were significant increases in the penetration values of all groups, with the addition of vegetable oil. It was observed that the highest increase in penetration value occurred in PTO7 group, whereas the lowest increase in penetration value was in $\mathrm{CAO} 3$ group. Penetration value is significant especially during the production of bituminous hot mixes for workability and flexibility of road coating. Increasing the penetration value makes bitumen become softer. This means an ease of processing for applications at very low temperatures and that cracking and breakage at low temperatures can be prevented.

When the reference and all other sample groups were examined, an elongation of $+100 \mathrm{~cm}$ observed in all the ductility results and it was determined that they behaved ductile against rupture, that is, the characteristics expected from the binder in the coating layer in structures was ensured. It was determined that the peeling strength of all samples was greater than $50 \%$. Thus, it can be stated that the adherence between aggregate and the binder is strong.
When the results of EDX analysis are examined, it was determined that vegetable oils, added in different proportions to the bituminous binder, caused occasionally increases and sometimes decreases in carbon, oxygen and sulfur contents compared to the reference sample.

When the sensitivity to water, surface wetting and hydrophobic properties of bitumen, which is the main scope and originality of the study, were examined, it was found that the sensitivity of bitumen to water can be reduced by adding vegetable oil. With the results of the analysis, it was determined that different vegetable oils added in different proportions, contribute to this characteristic of bitumen higher or lower levels. Studies have shown that bituminous binders modified with vegetable oils, contribute significantly to all physical, mechanical, and surface wetting properties. This way, significant data have been provided about reducing moisture damage, one of the biggest problems of roads, and eliminating the risk of accidents caused by surface defects.

\section{Declaration of Interest Statement}

The authors declare that they have no known competing financial interests or personal relationships that could have appeared to influence the work reported in this paper.

\section{Author Contribution Statement}

S. Serin: Conceptualization, Data Curation, Formal analysis, Investigation, Methodology, Project administration, Resources, Software, Supervision, Validation, Visualization, Writing - Original Draft, Writing - Review \& Editing - S. E. Demirezer: Data Curation, Formal analysis, Investigation, Methodology, Resources, Software, Validation, Visualization , Writing - Original Draft. 


\section{References}

[1] Singh, M., Kumar, P., \& Maurya, M. R. (2013). Strength characteristics of SBS modified asphalt mixes with various aggregates. Construction and Building Materials, 41, 815823. https://doi.org/10.1016/j.conbuildmat.2012.12.062

[2] Fernandes, A., \& Neves, J. (2014). Threshold values of pavement surface properties for maintenance purposes based on accidents modelling. International Journal of Pavement Engineering, 15(10), 917-924. https://doi.org/10.1080/10298436.2014.893324

[3] Yan, X., Radwan, E., \& Abdel-Aty, M. (2005). Characteristics of rear-end accidents at signalized intersections using multiple logistic regression model. Accident Analysis \& Prevention, 37(6), 983-995. https://doi.org/10.1016/j.aap.2005.05.001

[4] Lee, J., Nam, B., \& Abdel-Aty, M. (2015). Effects of pavement surface conditions on traffic crash severity. Journal of Transportation Engineering, 141(10), $04015020 . \quad$ https://doi.org/10.1061/(ASCE)TE.19435436.0000785

[5] Little, D. N., Allen, D. H., \& Bhasin, A. (2018). Chemical and mechanical processes influencing adhesion and moisture damage in hot mix asphalt pavements. In Modeling and design of flexible pavements and materials (pp. 123-186). Springer, Cham. https://doi.org/10.1007/978-3-31958443-0_4

[6] Tarefder, R. A., \& Arifuzzaman, M. (2011). A study of moisture damage in plastomeric polymer modified asphalt binder using functionalized AFM tips. Journal of Systemics, Cybernetics and Informatics, 9(5), 1-12.

[7] Selvavathi, V., Sekar, V. A., Sriram, V., \& Sairam, B. (2002). Modifications of bitumen by elastomer and reactive polymer-a comparative study. Petroleum science and technology, 20(5-6),

535-547. https://doi.org/10.1081/LFT-120003577

[8] Kibar, A. (2016). An investigation of droplet bubble and liquid jet dynamics on superhydrophobic and hydrophobic surfaces. Pamukkale University Journal of Engineering Sciences, 22(7), 613-619. https://dx.doi.org/10.5505/pajes.2016.07088

[9] Bağdat S., 2016 http://kimya.balikesir.edu.tr/seminerler/dokuman/20200 108kaderozturk.pdf

[10] Leja, J. (1982). Surface Chemistry of Froth Flotation Plenum. p. 758, New York.

[11] Evcin, A., Ersoy, B., Uygunoğlu, T., \& Güneş, i. (2018). Farklı mineral katkıların epoksi zemin kaplama malzemesinin ıslanmazlığına ve yüzey enerjisine etkisi. Gazi Üniversitesi Mühendislik Mimarlık Fakültesi Dergisi, 33(2), 599-610. https://doi.org/10.17341/gazimmfd.416368

[12] Le, N. L., \& Nunes, S. P. (2016). Materials and membrane technologies for water and energy sustainability. Sustainable Materials and Technologies, 7, 1-28. https://doi.org/10.1016/j.susmat.2016.02.001

[13] Arukalam, I. O., Oguzie, E. E., \& Li, Y. (2016). Fabrication of FDTS-modified PDMS-ZnO nanocomposite hydrophobic coating with anti-fouling capability for corrosion protection of Q235 steel. Journal of colloid and interface science, 484,

220-228. https://doi.org/10.1016/j.jcis.2016.08.064

[14] Zdziennicka, A., Szymczyk, K., \& Jańczuk, B. (2009). Correlation between surface free energy of quartz and its wettability by aqueous solutions of nonionic, anionic and cationic surfactants. Journal of colloid and interface science, 340(2),

243-248.

https://doi.org/10.1016/j.jcis.2009.08.040

[15] Gönül, N. (2000). Süspansiyon ve Emülsiyon Teknolojisi. Ankara Üniversitesi Eczacılık Fakültesi Eczacılık Teknolojisi Bölümü, Ankara, 93.

[16] Karaman, M., \& Uçar, T. (2016). Enhanced mechanical properties of low-surface energy thin films by simultaneous plasma polymerization of fluorine and epoxy containing polymers. Applied Surface Science, 362, 210-216. https://doi.org/10.1016/j.apsusc.2015.11.254

[17] Hiemenz, P.C., (1986). Principles of Colloid And Surface Chemistry, $2^{\text {nd }}$ Ed.; Marcel Dekker Inc., New York.

[18] Kapilashrami, A., Eskilsson, K., Bergström, L., \& Malmsten, M. (2004). Drying of oil-in-water emulsions on hydrophobic and hydrophilic substrates. Colloids and Surfaces A: Physicochemical and Engineering Aspects, 233(1-3), 155-161. https://doi.org/10.1016/j.colsurfa.2003.11.022

[19] Gao, Z., Zhai, X., Liu, F., Zhang, M., Zang, D., \& Wang, C. (2015). Fabrication of TiO2/EP super-hydrophobic thin film on filter paper surface. Carbohydrate polymers, 128, 24-31. https://doi.org/10.1016/j.carbpol.2015.04.014

[20] Azemar, F., Faÿ, F., Réhel, K., \& Linossier, I. (2015). Development of hybrid antifouling paints. Progress in Organic Coatings, 87, 10-19. https://doi.org/10.1016/j.porgcoat.2015.04.007

[21] Chrzan, K. L. (2007). Performance of hydrophobic epoxy insulators under industrial pollution.

[22] Syakur, A., Berahim, H., \& Rochmadi, T. (2012). Hydrophobic contact angle and surface degradation of epoxy resin compound with silicon rubber and silica. Electrical and Electronic Engineering, 2(5), 284-291. http://doi.org/10.5923/j.eee.20120205.07

[23] Mehmetalioğlu, C., Olgun, U., Şen, Ş., Şen, U., Akıncı, A., Akcan, E., \& Özüyağlı, A. (2017). Nano TiO2 dolgulu polimer esaslı hidrofobik kaplamanın yüzey özelliklerinin incelenmesi. Sakarya University Journal of Science, 21(2), 77-81. https://doi.org/10.16984/saufenbilder.296793

[24] Giovannini, G., Lucchesi, S., \& Cervelli, S. (1983). Waterrepellent substances and aggregate stability in hydrophobic soil. Soil Science, 135(2), 110-113.

[25] Tittarelli, F. (2009). Oxygen diffusion through hydrophobic cement-based materials. Cement and Concrete Research, 39(10), 924-928. https://doi.org/10.1016/j.cemconres.2009.06.021

[26] Wong, H. S., Barakat, R., Alhilali, A., Saleh, M., \& Cheeseman, C. R. (2015). Hydrophobic concrete using waste paper sludge ash.Cement and Concrete Research, 70, 9-20. https://doi.org/10.1016/j.cemconres.2015.01.005

[27] Tittarelli, F., \& Moriconi, G. (2008). The effect of silanebased hydrophobic admixture on corrosion of reinforcing steel in concrete. Cement and Concrete Research, 38(11), 1354-1357.

https://doi.org/10.1016/j.cemconres.2008.06.009

[28] Tittarelli, F., \& Moriconi, G. (2010). The effect of silanebased hydrophobic admixture on corrosion of galvanized reinforcing steel in concrete. Corrosion Science, 52(9), 2958-2963. https://doi.org/10.1016/j.corsci.2010.05.008

[29] Lal, S., Poulikakos, L., Jerjen, I., Vontobel, P., Partl, M. N., Derome, D., \& Carmeliet, J. (2017). Wetting and drying in hydrophobic, macroporous asphalt structures. Construction and Building Materials, 152, 82-95. https://doi.org/10.1016/j.conbuildmat.2017.06.145

[30] Zakerzadeh, M., Abtahi, S. M., Allafchian, A., \& Chamani, M. R. (2018). Examining the effect of different super 
hydrophobic nanomaterials on asphalt pavements. Construction and Building Materials, 180, 285-290. https://doi.org/10.1016/j.conbuildmat.2018.04.190

[31] Gao, Y., Qu, L., He, B., Dai, K., Fang, Z., \& Zhu, R. (2018). Study on effectiveness of anti-icing and deicing performance of super-hydrophobic asphalt concrete. Construction and Building Materials, 191, 270-280. https://doi.org/10.1016/j.conbuildmat.2018.10.009

[32] Nahvi, A., Sadoughi, M. K., Arabzadeh, A., Sassani, A., Hu, C., Ceylan, H., \& Kim, S. (2019). Multi-objective Bayesian optimization of super hydrophobic coatings on asphalt concrete surfaces. Journal of Computational Design and Engineering, 6(4), 693-704. https://doi.org/10.1016/j.jcde.2018.11.005

[33] Han, S., Yao, T., \& Yang, X. (2019). Preparation and antiicing properties of a hydrophobic emulsified asphalt coating. Construction and Building Materials, 220, 214227. https://doi.org/10.1016/j.conbuildmat.2019.06.021

[34] Han, S., Yao, T., Han, X., Hongwei, Z., \& Yang, X. (2020). Performance evaluation of waterborne epoxy resin modified hydrophobic emulsified asphalt micro-surfacing mixture. Construction and Building Materials, 249, 118835.

https://doi.org/10.1016/j.conbuildmat.2020.118835

[35] Dalhat, M. A., \& Adesina, A. Y. (2020). Utilization of micronized recycled polyethylene waste to improve the hydrophobicity of asphalt surfaces. Construction and Building Materials, 240, 117966. https://doi.org/10.1016/j.conbuildmat.2019.117966 